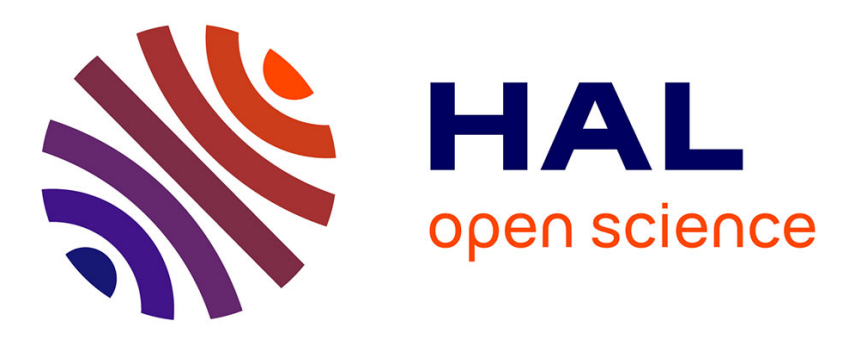

\title{
V-Band Velocity Estimation of Creeping Waves around the Human Body
}

Theodoros Mavridis, Luca Petrillo, Julien Sarrazin, Aziz Benlarbi-Delai, Philippe de Doncker

\section{To cite this version:}

Theodoros Mavridis, Luca Petrillo, Julien Sarrazin, Aziz Benlarbi-Delai, Philippe de Doncker. VBand Velocity Estimation of Creeping Waves around the Human Body. IEEE Antennas and Wireless Propagation Letters, 2015, 14, pp.313 - 316. 10.1109/LAWP.2014.2363558 . hal-01076197

\section{HAL Id: hal-01076197 \\ https://hal.science/hal-01076197}

Submitted on 21 Oct 2014

HAL is a multi-disciplinary open access archive for the deposit and dissemination of scientific research documents, whether they are published or not. The documents may come from teaching and research institutions in France or abroad, or from public or private research centers.
L'archive ouverte pluridisciplinaire HAL, est destinée au dépôt et à la diffusion de documents scientifiques de niveau recherche, publiés ou non, émanant des établissements d'enseignement et de recherche français ou étrangers, des laboratoires publics ou privés. 


\title{
V-Band Velocity Estimation of Creeping Waves around the Human Body
}

\author{
Theodoros Mavridis, Student Member, IEEE, Luca Petrillo, Julien Sarrazin, Member, IEEE, Aziz Benlarbi-Delaï, \\ Philippe De Doncker
}

\begin{abstract}
This letter investigates the phase velocity of an electromagnetic wave propagating between two sensors located on the human body surface by using the formulation of a creeping wave around a circular cylinder. The study is performed for both horizontal and vertical polarizations. The velocity is studied over the V-band. It is theoretically shown that the variation of the phase velocity is negligible over the bandwidth. Measurements are conducted on a metallic circular cylinder to assess the validity of these formulations. Then, an experimental validation of the circular cylinder assumption for the human body is performed. Deviation between the measurements and the theoretical circular model is between 2 and $3.5 \%$.
\end{abstract}

Index Terms-Body Area Networks, Millimeter waves, $60 \mathrm{GHz}$, Velocity, Creeping wave, V-Band.

\section{INTRODUCTION}

The emergence of $60 \mathrm{GHz}$ communicating systems presents multiple advantages for BANs such as antenna miniaturization [1], high data rates, low system interferences and bandwidth availability [2].

Static propagation models have been proposed for off- [3] and on-body [4]-[6] propagation. Also, dynamic measurements have been performed to evaluate the fading of the signal between two mounted devices [7], [8].

This letter proposes to analytically and experimentally study phase velocity of the creeping wave model developed in [4] which deals with the propagation of electromagnetic waves between two sensors on the human body at $60 \mathrm{GHz}$.

\section{Analytical Velocity of Creeping Waves}

\section{A. Creeping Wave Formulations}

In [4], a creeping wave formulation has been obtained from an asymptotic derivation of the radiation of a Hertzian dipole at the surface of a large dielectric cylinder [9]. The cylinder modeling the body is immersed in free-space. The cylinder has a radius $a$, a principal axis $\hat{z}$, relative permeability $\mu_{r}$ and relative complex permittivity $\varepsilon_{r}$ depending on the conductivity $\sigma$ by $\varepsilon_{r}=\varepsilon_{r}^{\prime}+\frac{\sigma}{j \omega \varepsilon_{0}}$ with $\varepsilon_{r}^{\prime}$ defined as the real part of the relative permittivity and $\varepsilon_{0}, \mu_{0}$ are respectively the free-space permittivity and permeability. A time dependence $e^{j \omega t}$ is assumed and suppressed, where $\omega=2 \pi f$ is the

T. Mavridis, L. Petrillo and P. De Doncker are with OPERA Dpt. Wireless Communications Group, Université Libre de Bruxelles (ULB), B1050 Brussels, Belgium e-mail: (tmavridi@ulb.ac.be ; lpetrillo@ulb.ac.be ; pdedonck@ulb.ac.be)

T. Mavridis, J. Sarrazin and A. Benlarbi-Delaï are with L2E Dept., Sorbonne Universités, UPMC Univ Paris 06, UR2, L2E, F-75005, Paris, France e-mail: (julien.sarrazin@upmc.fr; aziz.benlarbi_delai@umpc.fr)

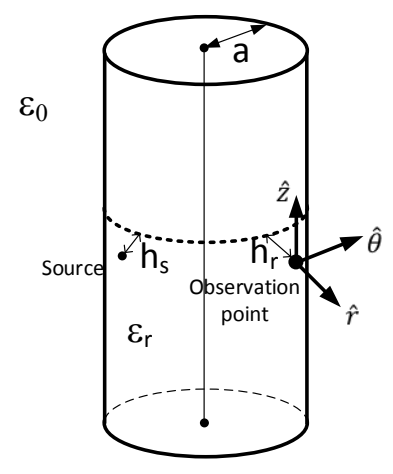

Fig. 1. Geometry of the analytical problem.

angular frequency and $f$ is the frequency. The Hertzian dipoles and the observation point are assumed to be respectively located at heights $h_{s}$ and $h_{r}$ from the cylinder surface. By assuming these heights small with respect to the radius, the distance between the source and the observation points is $\rho_{s}=a \theta$ where $\theta$ is the angle measured between the source and observation point. The geometry is presented in Fig. 1.

A uniform formulation has been provided for the Hertzian dipole oriented normally and tangentially to the surface of the cylinder. The case of the $\hat{r}$ oriented dipole is noted by the index $v$ and the electric field $E_{v}$ is along the $\hat{r}$ component. The index $h$ stands for a dipole oriented along $\hat{z}$ and the electric field $E_{h}$ is along $\hat{z}$ component.

It has been shown [3], [4] that the first creeping wave mode is dominant and it can be written as:

$$
E_{v, h}=c_{v, h} e^{-j\left(k+m \tau_{v, h} / a\right) \rho_{s}}
$$

In (1), the complex coefficient $c_{v, h}$ depends on $a, h_{s}, h_{r}$ and $\omega$ [4]. It is important to note that it also depends on $\rho_{s}$ but in magnitude ( $\rho_{s}$ have no impact on the phase). The wavenumber is defined as $k=\omega / c$ and $m=(k a / 2)^{1 / 3}$. The $\tau_{v, h}$ is the first zero of

$$
W^{\prime}\left(\tau_{v, h}\right)-q_{v, h} W\left(\tau_{v, h}\right)=0
$$

where $W(\tau)$ is a Fock-type Airy function defined with the standard Airy function $A(\cdot)$ as $W(\tau)=2 e^{j \pi / 6} \sqrt{\pi} A\left(e^{j 4 \pi / 3} \tau\right)$ and $q_{v, h}=-j m Z_{v, h}$ with $Z_{h}=\sqrt{\varepsilon_{r}}$ and $Z_{v}=1 / Z_{h}$. 


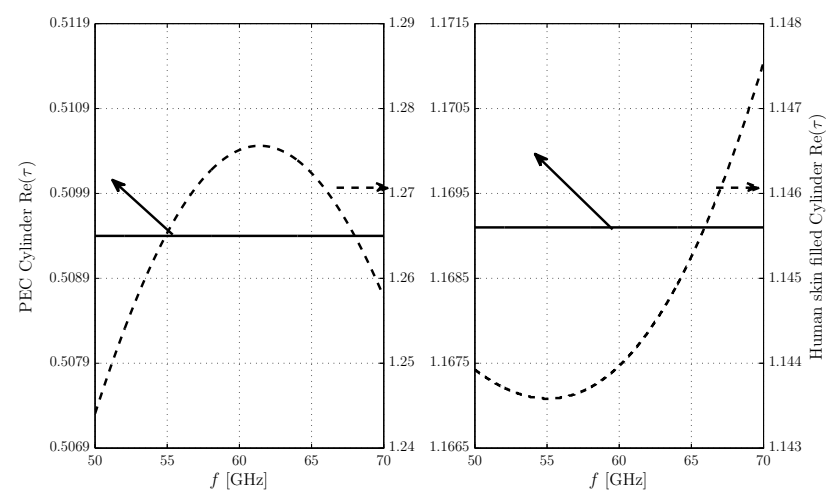

Fig. 2. Variation of the real part of $\tau_{v}$ (left) and $\tau_{h}$ (right) on the V-band with $a=0.2 \mathrm{~m}$. PEC cylinder result corresponds to the plain curve reported on the left axis while the cylinder having the same permittivity as the human skin to the the dotted line reported on the right axis.

\section{B. Velocity Assessment and Numerical Study}

The phase shift $\Delta \psi$ of a creeping wave propagating on a distance $d$ can be easily derived from (1):

$$
\Delta \psi=\left(k+m \operatorname{Re}\left(\tau_{v, h}\right) / a\right) d
$$

where $\operatorname{Re}(\cdot)$ stands for the real part. The phase $\Delta \psi$ of this correlation linearly varies with frequency [10], it can be written as:

$$
\Delta \psi=\frac{2 \pi f}{v_{\psi}^{v, h}} d
$$

Hence, the phase velocity $v_{\psi}^{v, h}$ is given by :

$$
v_{\psi}^{v, h}=\frac{2 \pi f}{(k+m \operatorname{Re}(\tau) / a)}=\frac{c}{1+\frac{m \operatorname{Re}\left(\tau_{v, h}\right)}{k a}}
$$

Equation (5) represents the phase velocity of a creeping wave around a circular cylinder. The phase depends basically on two parameters: the radius $a$ and the frequency $f$. The term $m / k a$ is trivial to evaluate since it is algebraic. However, the phase velocity also depend on the term $\operatorname{Re}\left(\tau_{v, h}\right)$ which is not straightforward to calculate since $\tau_{v, h}$ is the solution of (2). In the following, it is proposed to numerically evaluate $\operatorname{Re}\left(\tau_{v, h}\right)$ over the bandwidth. These simulations are conducted for a cylinder having the same permittivity as the human skin and a PEC cylinder.

The result is presented in Fig. 2. It is important to notice that the permittivity of the human skin is changing following the values obtained in [11]. In the case of a PEC cylinder, the variation of both $\tau_{v}$ and $\tau_{h}$ is less than $0.01 \%$.

The variation of $\operatorname{Re}\left(\tau_{v, h}\right)$ in the case of the human skin is maximum for the vertical polarization and is about $2 \%$. However, this variation is also negligible. Using basic propagation of uncertainty theory, it can trivially inferred that this $2 \%$ variation creates, in average, $0.04 \%$ error on the phase velocity. Then, in the following, the values of $\tau_{v, h}$ will be considered as constant over the whole bandwidth.

Since change of $\operatorname{Re}\left(\tau_{v, h}\right)$ over the bandwidth is negligible, equation (5) can be simplified by fixing the value of $\operatorname{Re}\left(\tau_{v, h}\right)$ to the value of the center of the bandwidth and neglecting the frequency variation of $\operatorname{Re}\left(\tau_{v, h}\right)$. This implies that phase velocity only depends on $k a$. It can be numerically shown that the maximum variation over the V-band of the phase velocity is about $0.5 \%$. Hence, the phase velocity can be considered as constant over the bandwidth. Table I summarize the $\tau_{v, h}$ parameter and related phase velocities.

TABLE I

MEAN VALUES OF $\tau_{v, h}$ AND $v_{\psi}$ OVER THE V-BAND FOR A PEC AND A HUMAN SKIN FILLED CYLINDERS.

\begin{tabular}{c|cccc}
\hline \hline \multirow{2}{*}{$a[\mathrm{~m}]$} & $\begin{array}{c}\operatorname{Re}\left(\tau_{v}\right)^{\text {Skin }} \\
\operatorname{Re}\left(\tau_{v}\right)^{\mathrm{PEC}}\end{array}$ & $\begin{array}{c}\left(v_{\psi}^{v}\right)^{\text {Skin }}[\mathrm{m} / \mathrm{s}] \\
\left(v_{\psi}^{v}\right)^{\mathrm{PEC}}[\mathrm{m} / \mathrm{s}]\end{array}$ & $\begin{array}{c}\operatorname{Re}\left(\tau_{h}\right)^{\text {Skin }} \\
\operatorname{Re}\left(\tau_{h}\right)^{\mathrm{PEC}}\end{array}$ & $\begin{array}{c}\left(v_{\psi}^{h}\right)^{\text {Skin }}[\mathrm{m} / \mathrm{s}] \\
\left(v_{\psi}^{h}\right)^{\mathrm{PEC}}[\mathrm{m} / \mathrm{s}]\end{array}$ \\
\hline \multirow{2}{*}{0.15} & 1.219 & $2.911 \times 10^{8}$ & 1.154 & $2.918 \times 10^{8}$ \\
& 0.509 & $2.962 \times 10^{8}$ & 1.169 & $2.916 \times 10^{8}$ \\
\hline \multirow{2}{*}{0.2} & 1.227 & $2.924 \times 10^{8}$ & 1.155 & $2.932 \times 10^{8}$ \\
& 0.509 & $2.968 \times 10^{8}$ & 1.169 & $2.930 \times 10^{8}$ \\
\hline \multirow{2}{*}{0.25} & 1.232 & $2.934 \times 10^{8}$ & 1.156 & $2.941 \times 10^{8}$ \\
& 0.509 & $2.973 \times 10^{8}$ & 1.169 & $2.940 \times 10^{8}$ \\
\hline \multirow{2}{*}{0.30} & 1.234 & $2.940 \times 10^{8}$ & 1.157 & $2.947 \times 10^{8}$ \\
& 0.510 & $2.976 \times 10^{8}$ & 1.169 & $2.946 \times 10^{8}$ \\
\hline \hline
\end{tabular}

It is important to note again that the variation of $\tau_{v, h}$ is negligible with the radius of the cylinder $a$.

\section{EXPERIMENTAL VALIDATION}

To assess the validity of the proposed model, two measurement campaigns have been conducted. The first one has been realized using a perfectly conducting (PEC) cylinder in order to precisely verify the theoretical path gain. The second campaign has been conducted on a human. Its purpose was to evaluate the validity of the model to emulate a real body although it has been developed for a cylinder.

\section{A. Experimental Velocity estimation method}

In [12], a frequency correlation analysis for wideband signals is proposed to evaluate the phase velocity of on-body waves. The correlation is estimated between two observation locations noted 1 and 2 spaced by a distance $d$. The complex correlation $\rho$ is given by:

$$
\rho=\frac{E\left[S_{1} S_{2}^{*}\right]}{\sqrt{E\left[\left|S_{1}\right|^{2}\right] E\left[\left|S_{2}\right|^{2}\right]}}
$$

where $S_{1}$ and $S_{2}$ are the frequency channel transfer functions between the source and the observation points 1 and 2,* denotes the complex conjugate operation and $E[]$ stands for the expect value that averages channel realisations.

The method proposes to estimate the coefficient $\left(2 \pi d / v_{\psi}\right)$ of equation (4) between the phase and the frequency for different distances $d$. Then, using the obtained coefficient with $d$, the phase velocity can be easily obtained. This method will be used in the following in order to assess analytically and experimentally the phase velocity of a creeping wave.

\section{B. PEC Measurement Campaign}

a) Experimental Set-up: The measurements were conducted with an Agilent E8361C VNA and U-band horn antennas (20 dB gain) in an anechoic chamber. To increase the 


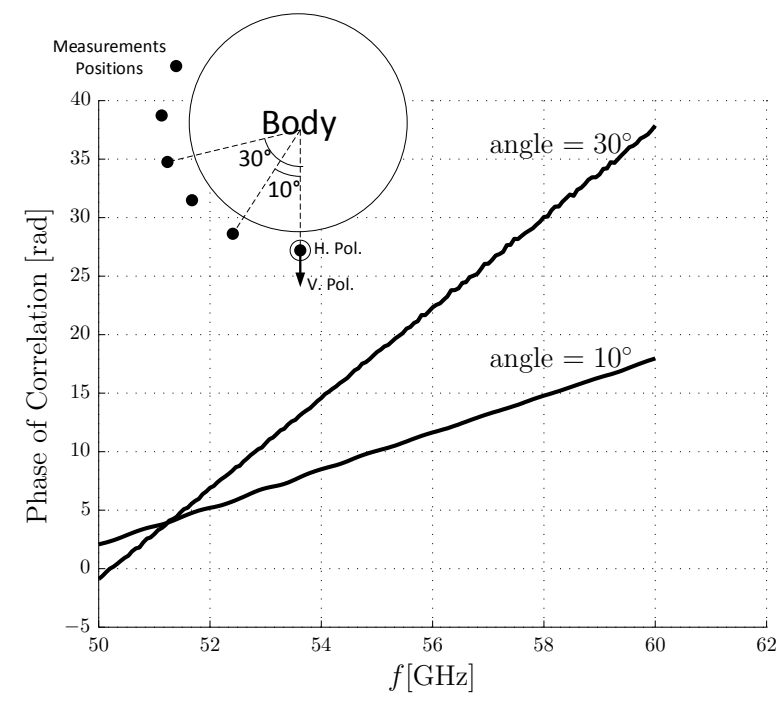

Fig. 3. PEC measurements. Exemple of measurement results for vertical polarization. Phase of the correlation with the frequency. The vertical and horizontal polarizations are recalled in the upper schema.

dynamic range, two amplifiers have been used (the first at the transmitter side and the second at the receiver side).To make the measurements, the brass cylinder has been vertically mounted on a rotor and could therefore rotate around its axis. The measurements have been performed from $0^{\circ}$ to $90^{\circ}$ with a $10^{\circ}$ step. A pyramidal horn antenna has been used as electromagnetic waves radiator. The antenna has a gain of $20 \mathrm{~dB}$ and a beamwidth of $10^{\circ}$. The aperture size is $2.3 \mathrm{~cm} \times 3 \mathrm{~cm}$. It has been mounted directly on the surface of the cylinder, at middle height. A field probe has been realized by fixing a second identical antenna on a vertical stand. The probe was then moved at the surface of the cylinder, at the same height as the source. The receiving $(\mathrm{Rx})$ and transmitting (Tx) horn antennas were placed tangentially to the cylinder to maximize the amount of power received from the creeping wave. The cylinder had a $0.2 \mathrm{~m}$ radius, a height of $1.2 \mathrm{~m}$ and the Rx horn antenna was placed at middle height. The measurements have been conducted from 50 to $60 \mathrm{GHz}$ with a $66.67 \mathrm{MHz}$ step. The IFbandiwdth of the VNA was $1 \mathrm{~Hz}$ in order to have the highest dynamic range possible.

The coaxial cables have about $6 \mathrm{~dB} / \mathrm{m}$ losses. To avoid the need of long distance cables and maximize the received power, the VNA was put inside the anechoic chamber and covered by absorbing material. Time gating has been performed to increase the dynamic range.

b) Results: The method presented in section III-A was used on the measurements. The phase of the correlation is drawn in Fig. 3 for two particular values as example. As expected, the phase varies linearly with respect to the frequency. For each couple of measurements positions, the slope of the curve is calculated and presented in Fig. 4. The latter is analytically equal to $2 \pi f d / v_{\psi}$.

This allows one to obtain easily the phase velocity of the creeping wave since the slope is given with the distance $d$.
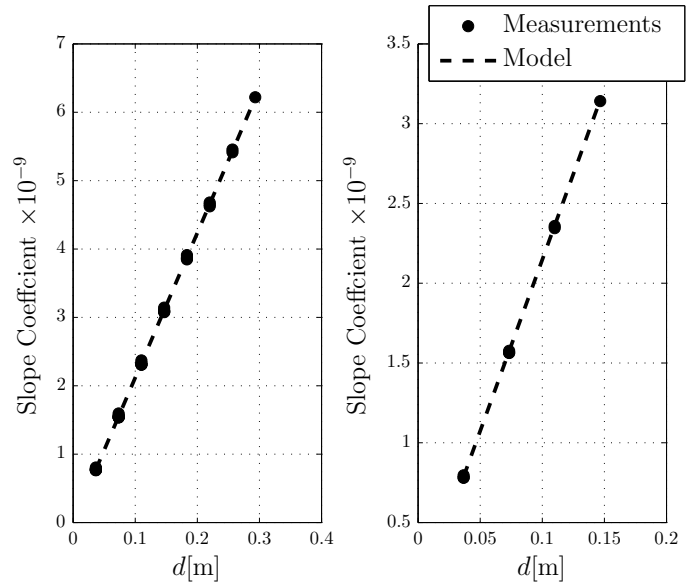

Fig. 4. Slope of the phase with the frequency for each distance in vertical (left) and horizontal (right) polarizations.

TABLE II

PEC MEASUREMENTS. COMPARISON BETWEEN MEASURED AND THEORETICAL PHASE VELOCITIES.

\begin{tabular}{ccc}
\hline \hline & Vertical Polarization & Horizontal Polarization \\
\hline Theoretical & $2.967 \times 10^{8} \mathrm{~m} / \mathrm{s}$ & $2.926 \times 10^{8} \mathrm{~m} / \mathrm{s}$ \\
Measured & $2.969 \times 10^{8} \mathrm{~m} / \mathrm{s}$ & $2.935 \times 10^{8} \mathrm{~m} / \mathrm{s}$ \\
\hline Relative Error & $0.08 \%$ & $0.33 \%$ \\
\hline
\end{tabular}

The dynamic range for vertical polarization being higher than for horizontal polarization, measurements have been restricted for fewer distances in the horizontal case.

The slope of these curves is theoretically equal to $2 \pi \mathrm{f} / v_{\psi}$. Hence, the phase velocity $v_{\psi}$ can be directly obtained from these figures.

Finally, in Table II, the theoretical and measured phase velocities are summarized. It can be shown that the comparison between the measurements and theoretical model shows a relative error of less than $1 \%$. These results allowed to assess the validity of the equations presented in section II. However, since the model is developed for body area networks, it is necessary to evaluate the accuracy of these equation on a real human body.

\section{Real Human Measurement Campaign}

c) Experimental Set-up: The measurements were conducted using a Rhode \& Schwarz ZVA-Z7 in a semi-anechoic room. Two V-band $(1.85 \mathrm{~mm})$ cables of 1 meter have been used with $10 \mathrm{~dB}$ of losses. To optimize the dynamic range, a $30 \mathrm{~dB}$ Low Noise amplifier have been placed at the receiver side. The transmitting and receiving antennas were standard Vband horns with $10 \mathrm{~dB}$ of gain. The measurements parameters and the human characteristics are summarized in Table. III.

The measurements have been carried out around the stomach of the subject and for each distance a collection of 10 measurements have been obtained and averaged. The channel has been obtained at each centimeter from 3 to $11 \mathrm{~cm}$ and the antenna have been placed on a belt explicitly designed for this measurement campaign. Time 
TABLE III

RELEVANT PARAMETERS FOR THE REAL human MEASUREMENT CAMPAIGN

\begin{tabular}{cc}
\hline \hline Parameter & Value \\
\hline$f_{\text {start }}$ & $55 \mathrm{GHz}$ \\
$f_{\text {stop }}$ & $65 \mathrm{GHz}$ \\
$f_{\text {step }}$ & $50 \mathrm{MHz}$ \\
VNA IFbandwidth & $1 \mathrm{kHz}$ \\
VNA Averaging & 1 \\
\hline Stomach Perimeter & $0.8 \mathrm{~m}$ \\
Equivalent Raduis & $12 \mathrm{~cm}$ \\
Height of the subject & $1.68 \mathrm{~m}$ \\
Gender & Male \\
\hline \hline
\end{tabular}
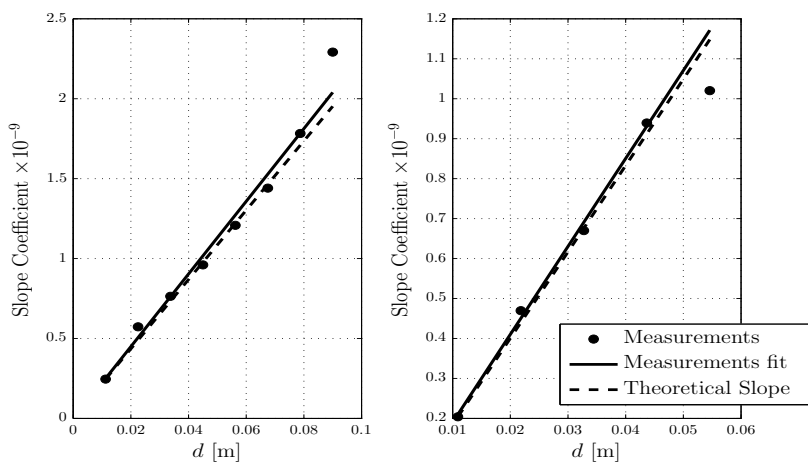

Fig. 5. Real Human measurements for vertical (left) and horizontal (right) polarizations. Slope of the phase with the frequency for each distance in horizontal polarization. The measurements with enough dynamic range have been kept.

gating has been used to isolate the creeping wave contribution.

d) Results: The results are presented in Fig. 5. It can be seen that the measurement varies linearly with distance. The theoretical slope has been obtained by using the formulation (5), and measurement fitting is obtained by minimizing the least squares error.

As can be observed in Table IV, the relative error between the theoretical model and the measured velocity is between 2 and $3.5 \%$. This can be easily explained by the human body geometry around the stomach which is not an exact circular cylinder. However, as seen, the circular cylinder is a good approximation of the human body for propagation around the human stomach.

\section{CONCLUSION}

In this paper, a creeping wave formulation for both vertical and horizontal polarized electromagnetic waves travelling on

TABLE IV

REAL HUMAN MEASUREMENTS. COMPARISON BETWEEN MEASURED AND THEORETICAL PHASE VELOCITIES.

\begin{tabular}{ccc}
\hline \hline & Vertical Polarization & Horizontal Polarization \\
\hline Theoretical & $2.899 \times 10^{8} \mathrm{~m} / \mathrm{s}$ & $2.906 \times 10^{8} \mathrm{~m} / \mathrm{s}$ \\
Measured & $2.799 \times 10^{8} \mathrm{~m} / \mathrm{s}$ & $2.846 \times 10^{8} \mathrm{~m} / \mathrm{s}$ \\
\hline Relative Error & $3.57 \%$ & $2.10 \%$ \\
\hline \hline
\end{tabular}

a circular path around a cylinder are studied and their phase velocity is assessed. It is shown that variation of the latter is negligible over the V-band. Measurements on the stomach of a real human body show that the phase velocity of the creeping waves can be modelled with a circular cylinder filled with a dielectric material equivalent to the human skin. The phase velocity of the creeping wave around a human body with $12 \mathrm{~cm}$ equivalent radius for vertical polarization is $2.799 \times 10^{8}$ $\mathrm{m} / \mathrm{s}$ and $2.846 \times 10^{8} \mathrm{~m} / \mathrm{s}$ for the horizontal one. The cylinder model shows a maximum error for vertical polarization and it is about $3.5 \%$. Since the phase velocity can be considered constant over the bandwidth, propagation around the human body can be assumed non-dispersive in the $\mathrm{V}$ band.

\section{ACKNOWLEDGMENT}

The authors would like to thank Mr Y. Chatelon for cylinder manufacturing and Prof. B. Huyart, Mr A. Khy and Dr. R. Mohellebi for their helpful advice and willingness. This work is supported by grants of the Fonds de la Recherche pour l'Industrie et l'Agriculture (FRIA), Belgium.

\section{REFERENCES}

[1] L. Petrillo, T. Mavridis, J. Sarrazin, J.-M. Dricot, A. Benlarbi-Delai, and P. De Doncker, "Ban working frequency: A trade-off between antenna efficiency and propagation losses," in Antennas and Propagation (EuCAP), 2014 8th European Conference on, April 2014, pp. 33683369.

[2] A. Pellegrini, A. Brizzi, L. Zhang, K. Ali, Y. Hao, X. Wu, C. Constantinou, Y. Nechayev, P. Hall, N. Chahat et al., "Antennas and propagation for body-centric wireless communications at millimeter-wave frequencies: A review [wireless corner]," Antennas and Propagation Magazine, IEEE, vol. 55, no. 4, pp. 262-287, 2013.

[3] T. Mavridis, L. Petrillo, J. Sarrazin, D. Lautru, A. Benlarbi-Delaï, and P. De Doncker, "Theoretical and experimental investigation of a $60 \mathrm{GHz}$ off-body propagation model," IEEE Trans. Antennas Propag., vol. 62, no. 1, pp. 393-402, 2014.

[4] L. Petrillo, T. Mavridis, J. Sarrazin, D. Lautru, A. Benlarbi-Delaï, and P. De Doncker, "Analytic creeping wave model and measurements for $60 \mathrm{GHz}$ body area networks," IEEE Trans. Antennas Propag., Accepted for publication.

[5] N. Chahat, G. Valerio, M. Zhadobov, and R. Sauleau, "On-body propagation at $60 \mathrm{ghz}$, , Antennas and Propagation, IEEE Transactions on, vol. 61, no. 4, pp. 1876-1888, April 2013.

[6] A. Guraliuc, M. Zhadobov, G. Valerio, N. Chahat, and R. Sauleau, "Effect of textile on the propagation along the body at $60 \mathrm{GHz}$," Antennas and Propagation, IEEE Transactions on, vol. 62, no. 3, pp. 1489-1494, March 2014.

[7] L. Petrillo, T. Mavridis, J. Sarrazin, A. Benlarbi-Delaï, and P. De Doncker, "Dynamic on-body measurement results at $60 \mathrm{GHz}$," IEEE Trans. Antennas Propag., submitted.

[8] Y. I. Nechayev, X. Wu, C. C. Constantinou, and P. S. Hall, "Millimetrewave path-loss variability between two body-mounted monopole antennas," IET Microwaves, Antennas \& Propagation, vol. 7, no. 1, pp. 1-7, 2013.

[9] R. Paknys and N. Wang, "High-frequency surface field excited by a magnetic line source on an impedance cylinder," Antennas and Propagation, IEEE Transactions on, vol. 35, no. 3, pp. 293-298, 1987.

[10] R. Vaughan and J. Andersen, Channels, propagation and antennas for mobile communications. IEE, London, United Kingdom, 2003.

[11] P. A. Hasgall, E. Neufeld, M.-C. Gosselin, A. Klingenböck, and N. Kuster, "IT'IS database for thermal and electromagnetic parameters of biological tissues, version 2.2," July 11th, 2012. [Online]. Available: http://www.itis.ethz.ch/database

[12] S. Van Roy, O. Oestges, F. Horlin, and P. De Doncker, "On-body propagation velocity estimation using ultra-wideband frequency-domain spatial correlation analyses," Electronics Letters, vol. 43, no. 25, pp. 1405 - 1406, 2007. 